\title{
Research Reports \\ Thidiazuron- and Zeatin-induced High-frequency Shoot Regeneration from Leaf and Shoot-tip Explants of Strawberry
}

\author{
Fatemeh Haddadi ${ }^{1,4}$, Maheran Abd Aziz ${ }^{1,2,4}$, \\ Hossein Kamaladini ${ }^{1,3}$, and Seyed Ali Ravanfar ${ }^{1}$
}

ADDITIONAL INDEX WORDS. cytokinin, MS medium, organogenesis

\begin{abstract}
Summary. Strawberry (Fragaria $\times$ ananassa cv. Camarosa) was evaluated to determine a high-frequency shoot regeneration response for leaf and shoot-tip explants. For direct organogenesis from strawberry leaves, combinations of moderate concentrations of thidiazuron $[\operatorname{TDZ}(0,2$, and $4 \mu \mathrm{M})]$ and 6-benzylaminopurine $[\operatorname{BAP}(0,4$, and $9 \mu \mathrm{M})]$ added into medium containing Murashige and Skoog $(\mathrm{MS})$ basal salts were compared. The most shoots regenerated per leaf explant were observed with 4- $\mu$ M TDZ. Regeneration from shoot tips was evaluated with 0-, 2-, 4-, 8-, and 16- $\mu \mathrm{M}$ zeatin, kinetin, or 6- $\alpha, \alpha$-dimethylallylamino purine (2ip) tested individually. Optimum shoot proliferation was achieved from shoot-tip explants on medium containing 4- $\mu \mathrm{M}$ zeatin. Rooting was best without cytokinins in the

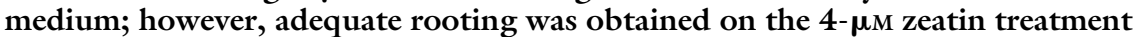
as well.
\end{abstract}

$\mathrm{C}$ ultivated strawberry, a member of the Rosaceae family and the genus Fragaria, is an important crop consisting of more than 20 species (Gaafar and Saker, 2006) and numerous cultivars grown commercially in over 70 countries (Sakila et al., 2007). Strawberries together

The authors gratefully acknowledge the excellent assistance of Mahmood Danaei in the statistical analysis and Professor Barbara M. Reed. This research was supported by RUGS project no. 01/01/07/ 0300RU.

${ }^{1}$ Department of Agriculture Technology, Faculty of Agriculture, Universiti Putra Malaysia, Serdang, Selangor, 43400, Malaysia

${ }^{2}$ Laboratory of Plantation Crops, Institute of Tropical Agriculture, Universiti Putra Malaysia, Serdang, Selangor, 43400, Malaysia

${ }^{3}$ Department of Biology, Faculty of Science, University of Zabol, Zabol, Sistan and Bloochestan, Iran

${ }^{4}$ Corresponding author. E-mail: maheran@agri.upm. edu.my; haddadifatemeh@yahoo.com. with grapes (Vitis vinifera) and cherries (Prunus sp.) are among the few sources of ellagic acid, a polyphenol antioxidant, which has been shown to prevent healthy cells from turning into cancerous tissue (Sakila et al., 2007). Strawberry production in Malaysia is concentrated in the highland areas, especially in the Cameron
Highlands (lat. $42^{\circ} 8^{\prime} 60^{\prime \prime} \mathrm{N}$, long. $101^{\circ} 27^{\prime} 0^{\prime \prime} \mathrm{E}, 1448-\mathrm{m}$ elevation) (Sharif et al., 2006). The most popular cultivar for commercial cultivation in the Cameron Highlands is Camarosa. 'Camarosa' fruit has good flavor, being very sweet with very firm, brilliant red flesh throughout. The excellent internal and external color of the fruit is another good characteristic of 'Camarosa' (Voth et al., 1994).

Adventitious shoot regeneration in cultivated strawberry was demonstrated using several types of in vitro cultured explants. However, the highest regeneration success was obtained from leaf explants for most of the cultivars analyzed (Passey et al., 2003). Nonetheless, strawberry cultivars with diverse genetic backgrounds responded differently to the range of regeneration protocols (Passey et al., 2003).

Hormonal balance is one of the key factors influencing plant regeneration from strawberry explants. Thidiazuron, a substituted phenylurea with its cytokinin- and auxin-like effects, is the most recently studied of the cytokinins (Debnath and Teixeira da Silva, 2007). There are many reports of improved regeneration capacity with TDZ compared with other cytokinins (Sriskandarajah et al., 2001; Zhang et al., 2001). The effectiveness of TDZ as a phenylurea type in combination with BAP as an adenine-type cytokinin on in vitro leaf regeneration of strawberry has not been demonstrated. The first objective of this study was to investigate the optimal conditions for in vitro plant regeneration via organogenesis from leaf explants of strawberry using combinations of TDZ and BAP. The use of zeatin as an adenine-type cytokinin to induce adventitious shoot formation has increased during the last few years. There are no reports on the effect of zeatin on strawberry shoot-tip proliferation. The second objective of this study

\begin{tabular}{llll}
\hline $\begin{array}{l}\text { Units } \\
\begin{array}{l}\text { To convert U.S. to SI, } \\
\text { multiply by }\end{array}\end{array}$ & U.S. unit & SI unit & $\begin{array}{l}\text { To convert SI to U.S., } \\
\text { multiply by }\end{array}$ \\
\hline 29.5735 & $\mathrm{fl} \mathrm{oz}$ & $\mathrm{mL}$ & 0.0338 \\
7.8125 & $\mathrm{fl} \mathrm{oz} / \mathrm{gal}$ & $\mathrm{mL} \cdot \mathrm{L}^{-1}$ & 0.1280 \\
3.7854 & gal & $\mathrm{L}$ & 0.2642 \\
2.54 & inch $(\mathrm{es})$ & $\mathrm{cm}$ & 0.3937 \\
6.4516 & inch & $\mathrm{cm}^{2}$ & 0.1550 \\
0.5933 & $\mathrm{lb} / \mathrm{yard}^{3}$ & $\mathrm{~kg} \cdot \mathrm{m}^{-3}$ & 1.6856 \\
1 & $\mathrm{mmho} / \mathrm{cm}$ & $\mathrm{mS} \cdot \mathrm{cm}^{-1}$ & 1 \\
28.3495 & $\mathrm{Oz}$ & $\mathrm{g}$ & 0.0353 \\
1 & $\mathrm{ppm}$ & $\mathrm{mg} \cdot \mathrm{L}^{-1}$ & 1 \\
$\left({ }^{\circ} \mathrm{F}-32\right) \div 1.8$ & ${ }^{\circ} \mathrm{F}$ & ${ }^{\circ} \mathrm{C}$ & $\left({ }^{\circ} \mathrm{C} \times 1.8\right)+32$
\end{tabular}


was to determine the most efficient regeneration system, along with root formation from shoot tips using zeatin and $2 \mathrm{ip}$ as the naturally occurring cytokinins and kinetin as the synthetic cytokinin.

\section{Materials and methods}

SHOOT REgENERATION USING LEAF EXPLANTS. Medium used consisted of MS basal salts (Murashige and Skoog, 1962), B 5 vitamins (Gamborg et al., 1968), 3\% sucrose, and 0.28\% Phytagel (Sigma-Aldrich, St. Louis, MO). Growth regulators included 0-, $2-$, and 4- $\mu \mathrm{M}$ TDZ in combination with $0-, 4-$, and 9- $\mu \mathrm{M}$ BAP. The medium was dispensed in $60-\mathrm{mL}$ aliquots into $250-\mathrm{mL}$ erlenmeyer flasks. Trifoliate leaves of 'Camarosa' strawberry were obtained from one-month-old in vitro stock plants propagated from runner-tips of strawberry on MS basal salts and vitamins. The edges of the leaves were cut and incisions made on the surface and then cultured with the abaxial side down on the regeneration medium (Fig. 1A). All cultures were maintained in a culture room at $25 \pm$ $2{ }^{\circ} \mathrm{C}$ under a 16 -h photoperiod of $40 \mu \mathrm{mol} \cdot \mathrm{m}^{-2} \cdot \mathrm{s}^{-1}$ light intensity provided by cool white fluorescent tubes. Each treatment consisted of 10 explants and the experiment was repeated three times $(n=30)$. The percentage of explants producing shoots and number of shoots produced per explant were recorded in each treatment after 4 weeks of culture.

SHOOT REGENERATION USING SHOOT-TIP EXPLANTS. Shoot tips ( 5 to $7 \mathrm{~mm}$ ) were collected from the onemonth-old in vitro stock plants propagated from runner-tips mentioned earlier. Zeatin, kinetin, or 2 ip at 0,2 , 4,8 , or $16 \mu \mathrm{M}$ was added separately into medium consisting of MS basal salts with $\mathrm{B}_{5}$ vitamins, $3 \%$ sucrose, and $0.28 \%$ Phytagel. The medium was dispensed in $60-\mathrm{mL}$ aliquots into $250-\mathrm{mL}$ erlenmeyer flasks. The tips were subcultured three times on the same treatment at 4-week intervals. Each treatment consisted of 10 explants and the experiment was repeated three times. The percentage of explants producing shoots, number of shoots per explant, and percentage of explants producing roots were recorded after 12 weeks of culture.

EXPERIMENTAL DESIGN AND STATISTICAL ANALYSIS. The shoot regeneration experiment using leaf explants was arranged in a completely
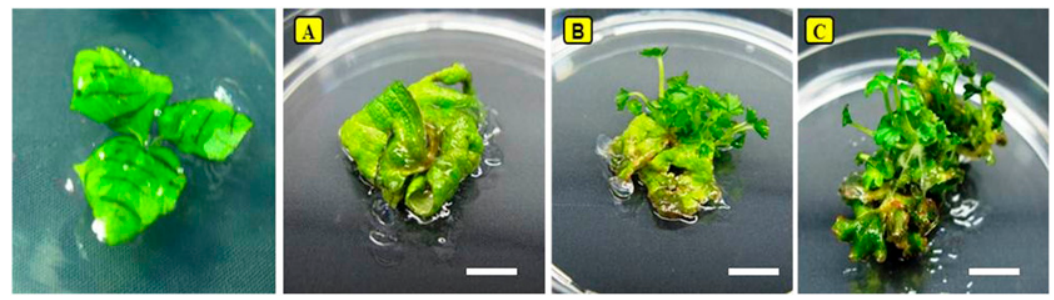

Fig. 1. Shoot regeneration in strawberry after 4 weeks of culture: (A) trifoliate leaves cut on the sides and incisions made on the surface $($ bar $=0.7 \mathrm{~cm})$, (B) without cytokinin $(\mathrm{bar}=0.8 \mathrm{~cm}),(\mathrm{C})$ with $4-\mu_{M}$ thidiazuron $(\mathrm{TDZ})$ and $9-\mu \mathrm{M}$ 6-benzylaminopurine $(\mathrm{BAP})(\mathrm{bar}=1 \mathrm{~cm}),(\mathrm{D})$ with $4-\mu \mathrm{M}$ TDZ without BAP $($ bar $=1 \mathrm{~cm}) ; 1 \mathrm{~cm}=0.3937$ inch.

Table 1. Analysis of variance of factorial analysis for number of shoots produced per explant and percentage of explants producing shoots in 'Camarosa' strawberry. Significant interaction was achieved between the thidiazuron (TDZ) and 6-benzylaminopurine (BAP) concentrations.

\begin{tabular}{lccccc}
\hline Source of variation & df & Sum of squares & Mean squares & F value & $P>\mathbf{F}$ \\
\hline Number of shoots per explant & & & & \\
BAP concn & 2 & 144.2 & 72.1 & $453.8^{* *}$ & $<0.0001$ \\
TDZ concn & 2 & 104.2 & 52.1 & $327.9^{* *}$ & $<0.0001$ \\
BAP $\times$ TDZ & 4 & 282 & 70.5 & $443.7^{* *}$ & $<0.0001$ \\
Error & 18 & 2.86 & 0.16 & & \\
Total & 26 & 533.3 & & & \\
CV $=7.8 \%$ & & & $R^{2}=0.99$ & &
\end{tabular}

Percentage of explants forming shoots

\begin{tabular}{lrccrl} 
BAP concn & 2 & 718.5 & 359.3 & $16.17^{* *}$ & $<0.0001$ \\
TDZ concn & 2 & 9429.6 & 4714.8 & $212.2^{* *}$ & $<0.0001$ \\
BAP $\times$ TDZ & 4 & 7859.3 & 1964.8 & $88.42^{* *}$ & $<0.0001$ \\
Error & 18 & 400 & 22.22 & & \\
Total & 26 & 18407.4 & & & \\
$\mathrm{CV}=9.8 \%$ & & & $R^{2}=0.98$ & & \\
\hline
\end{tabular}

**Significance level.

randomized design (CRD) based on factorial experiment. The shoot regeneration experiment using shoot tips was arranged in a CRD as a single factor experiment. Data were analyzed using analysis of variance and when treatments were significant, means were separated at the 5\% level using Duncan's multiple range test (SAS version 9.0; SAS Institute, Cary, NC).

\section{Results}

SHOOT REgENERATION FROM LEAF EXPLANTS. Leaves started to produce shoots after $10 \mathrm{~d}$ of culture in the presence of TDZ and after $15 \mathrm{~d}$ in the presence of BAP. Figure 1 shows shoot regeneration from strawberry leaf explants after 4 weeks of culture. No callus formation was observed in medium with TDZ and BAP. There were significant interactions between TDZ and BAP concentrations for the number of shoots produced per explant and percentage of explants with shoots (Table 1 ). The most shoots produced per explant (14.3) and highest percentage of explants with shoots $(90 \%)$ were obtained after 4 weeks of culture on 4- $\mu \mathrm{M}$ TDZ without BAP (Fig. 2A and B). In the absence of TDZ, 4- $\mu \mathrm{M}$ BAP produced the most shoots per explant (6.3) after one month of culture, which was less than half of the amount produced with the same concentration of TDZ (Fig. 2A). In addition, only $53.33 \%$ regeneration of explants was obtained when only 4- $\mu \mathrm{M}$ BAP was included in the medium (Fig. 2B).

Increasing the TDZ concentration from 2 to $4 \mu \mathrm{M}$ in the presence of $4-\mu \mathrm{M}$ $\mathrm{BAP}$ reduced the number of shoots produced per explant, whereas the same TDZ increase with 9- $\mu \mathrm{M}$ BAP increased both the number of shoots produced per explant and the percentage of explants with shoots (Fig. 2A and B).

SHOOT REGENERATION FROM SHOOT-TIP EXPLANTS. The addition 

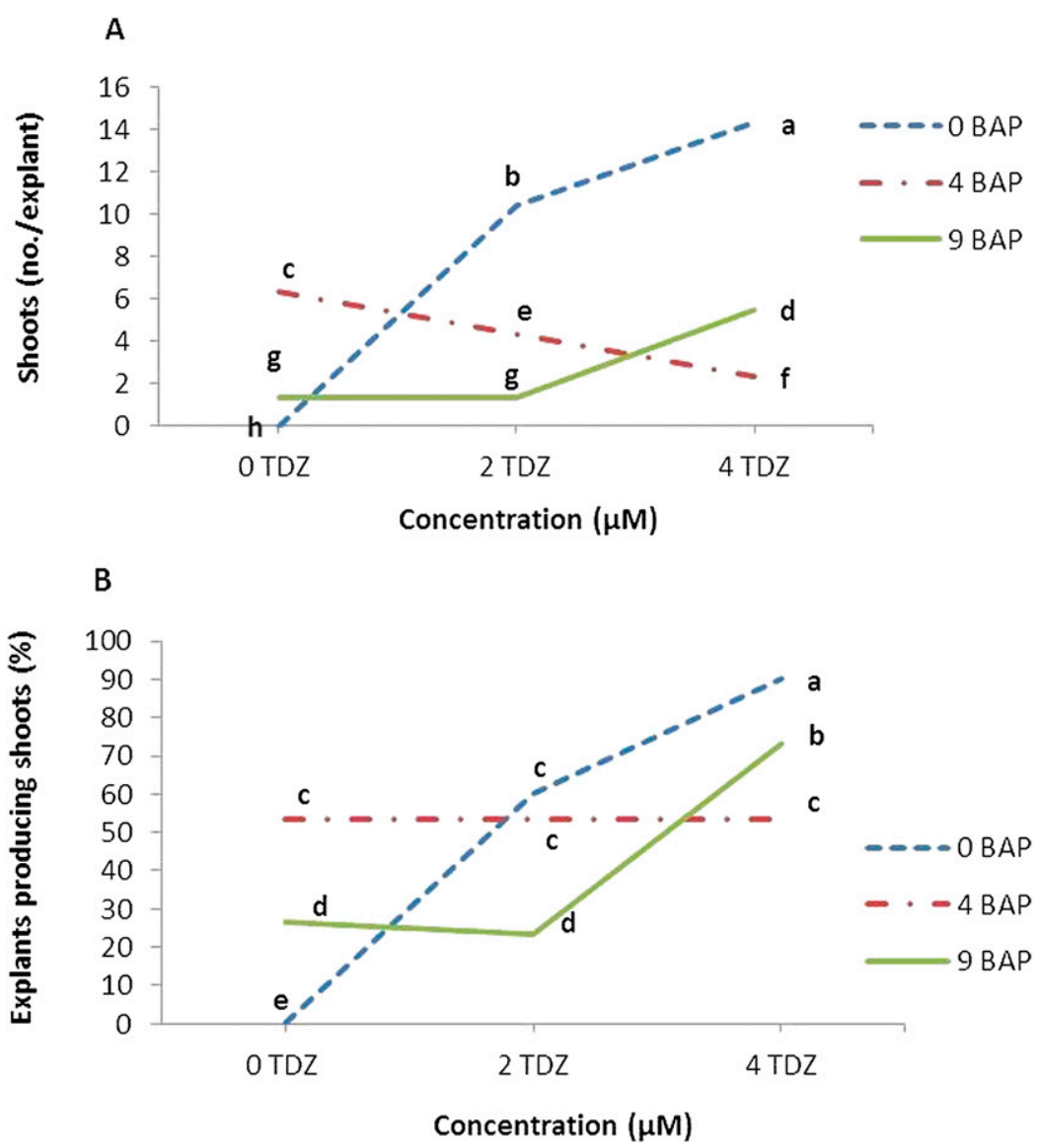

Fig. 2. Effect of 6-benzylaminopurine (BAP) at 0,4 , and $9 \mu \mathrm{M}$ in combination with thidiazuron (TDZ) on strawberry leaves after 4 weeks of culture: (A) number of shoots produced per explant, (B) percentage of explants producing shoots. The values represent the means of three independent experiments. Means followed by the same letter(s) are not significantly different based on Duncan's multiple range test at $\alpha=0.05$.

of zeatin, 2ip, and kinetin to the medium significantly increased the number of shoots produced per explant and percentage of explants with shoots (Fig. 3A and B). Shoots started to proliferate by the first week of culture in the presence of cytokinins. The most shoots produced per explant (16.1), with $97 \%$ of explants responding, occurred with 4- $\mu \mathrm{M}$ zeatin after 12 weeks of culture. Increasing the concentration of zeatin to 8 and $16 \mu \mathrm{M}$ reduced the shoots produced per explant (Fig. 3A).

Increasing the concentration of kinetin from 2 to $16 \mu \mathrm{m}$ enhanced the number of shoots produced per explant and percentage of explants with shoots from strawberry shoot tips to 11.3 shoots produced per explant and $90 \%$ of explants with shoots on $16-\mu \mathrm{M}$ kinetin (Fig. 3A and B).

The effect of 2 ip on shoot proliferation from strawberry shoot tips showed an inconsistent result in terms of number of shoots produced per explant compared with zeatin and kinetin. The most shoots per explant (7.8) was on medium with $8-\mu \mathrm{M} 2 \mathrm{ip}$ and $83.3 \%$ of the explants produced shoots. Overall, 2ip did not result in high shoot production compared with treatments with zeatin and kinetin.

Shoots produced on the best zeatin, kinetin, and 2ip concentrations were vigorous and grew normally (Fig. 4). Root formation occurred along with shoot proliferation after the first subculture on all cytokinin treatments as well as on the hormonefree MS medium. After the third subculture, the highest percentage of explants producing roots $(93.3 \%)$ was on the hormone-free medium (Fig. 3C). With cytokinin treatments, the highest percentages of explants producing roots were with $2-\mu \mathrm{M}$ zeatin $(67 \%)$, with $4-$ and $16-\mu \mathrm{M}$ kinetin (53\%), and with 2- $\mu_{\mathrm{M}} 2 \mathrm{ip}(73 \%)$.

\section{Discussion}

SHOOT REgENERATION FROM LEAF EXPLANTS. Our study found significantly more shoots per explant (14.3) and explants with shoots (90\%) were obtained with 4- $\mu_{\mathrm{M}} \mathrm{TDZ}$ after 4 weeks of culture. A high frequency of direct shoot regeneration from leaves of strawberry 'Camarosa' was reported by Mohamed et al. (2007) after 8 weeks of culture on MS medium containing 9- $\mu \mathrm{M}$ TDZ, with eight shoots per explant and $75 \%$ of the explants producing shoots. However, we found that a lower concentration of TDZ was more suitable and economical in a shorter time for shoot regeneration from leaves of 'Camarosa'. TDZ often promoted callus formation, whereas shoot growth was inhibited. In addition, callus formation increased with the number of subcultures while shoot growth was consistently impaired as reported by Gomes et al. (2010). However, in this study, callus was not formed during regeneration of 'Camarosa'. Indeed, it confirmed that by applying TDZ at low concentrations, callus formation could be harnessed. A regeneration protocol with no callus phase has a marked advantage for transformation; however, it may not be completely free from somaclonal variation (Husaini et al., 2008).

We found that the most shoots per explant were produced on MS medium containing 4- $\mu \mathrm{M}$ BAP without TDZ (6.3) and 53\% of the explants produced shoots. According to Zebrowska and Hortynski (2002), MS medium with 14.2 - or $28.4-\mu \mathrm{M}$ BAP was optimal for regenerating strawberry shoots from leaves. In mulberry (Morus sp.), 8.88- $\mu$ M BAP was sufficient to induce 6.4 shoots per leaf explant; increasing the BAP concentration decreased the number and length of shoots formed per explant (Chitra and Padmaja, 2005). However, based on our results, increasing the concentration of BAP to $9 \mu \mathrm{M}$ reduced the number of shoots produced per explant and the percentage of explants producing shoots from strawberry leaves.

One of the important factors affecting regeneration efficiency is plant cultivar (Gruchala et al., 2004; Passey et al., 2003; Sorvari et al., 1993). On medium with optimal hormonal balance, Gruchala et al. (2004) obtained 
A

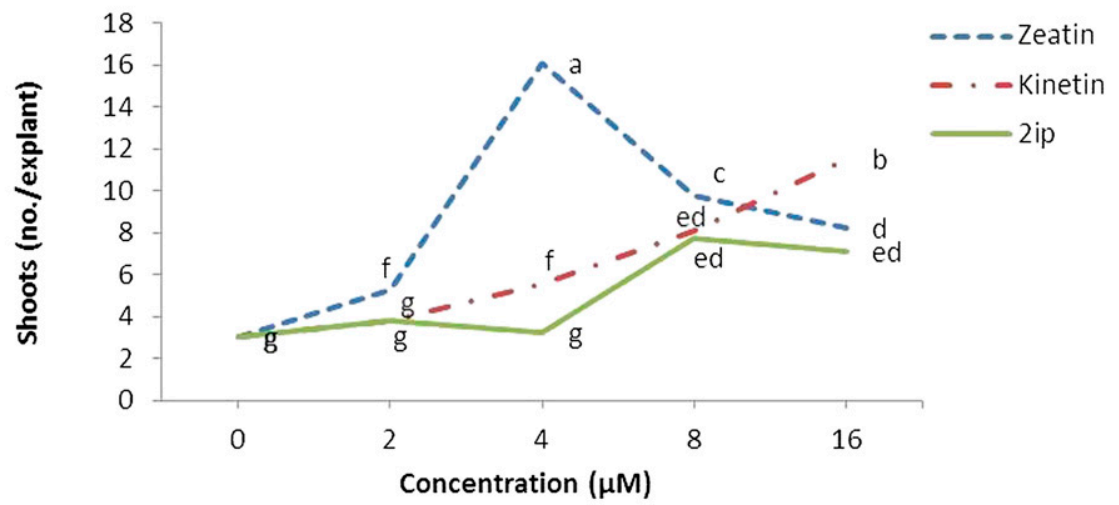

B

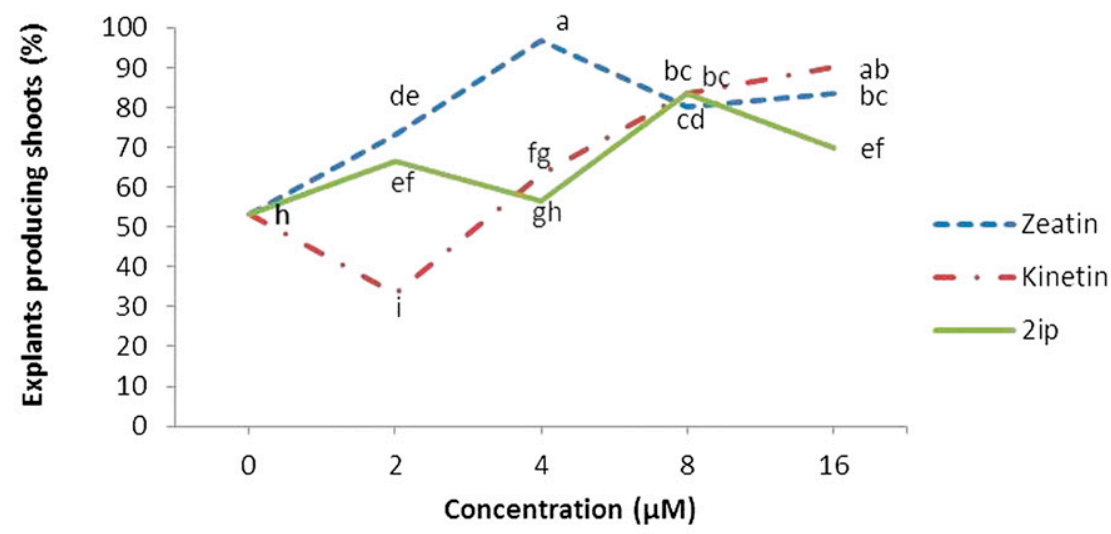

C

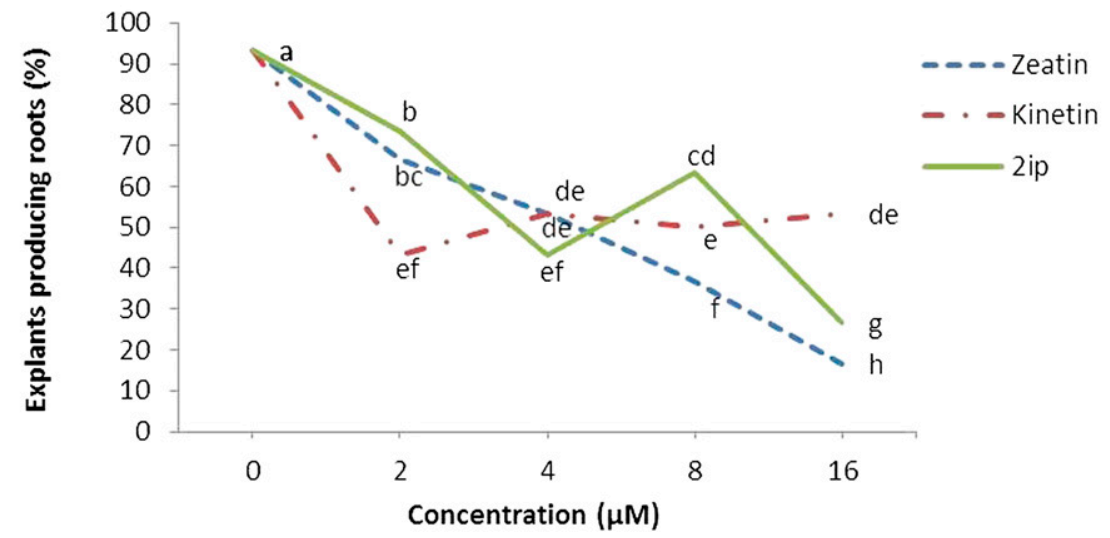

Fig. 3. Effect of zeatin, kinetin, and 6- $\alpha, \alpha$-dimethylallylamino purine (2ip) on shoot tips of strawberry after 12 weeks of culture: (A) number of shoots produced per explant, (B) percentage of explants producing shoots, (C) percentage of explants producing roots. The values represent the means of three independent experiments. Means followed by the same letter(s) are not significantly different based on Duncan's multiple range test at $\alpha=0.05$.

3.5 shoots per explant in strawberry 'Induka' while only 1.8 shoots per explant were obtained for 'Elista' and no regeneration occurred from leaf explants when auxins were absent. Khan et al. (2006) obtained shoot regeneration from leaves of tomato by adding $\alpha$-naphthalene acetic acid and BAP. In contrast, Compton and Gray (1993) found increased callus production and decreased shoot formation in watermelon (Citrullus lanatus) when indole-3-acetic acid was added to medium with BAP. However, in this study, our results from leaf explants of 'Camarosa' showed that regeneration could occur with TDZ and BAP either alone or in combination, and without auxins.

Several authors studied dual cytokinin effects on shoot regeneration (Dobranszki and Teixeira da Silva, 2010). According to Yonghua et al. (2005) and Landi and Mezzetti (2006),
TDZ in combination with IBA promoted high shoot regeneration from strawberry leaves of some octaploid cultivars. Husaini and Srivastava (2006) reported a high frequency of direct shoot regeneration from strawberry leaves on a modified MS medium containing $\mathrm{B}_{5}$ vitamins, $2 \%$ glucose, 5- $\mu_{M}$ TDZ, 2- $\mu_{M}$ IBA, and 4- $\mu_{M}$ $\mathrm{BAP}$. There are no reports on the use of a combination of two cytokinins (TDZ and BAP) without auxin on shoot regeneration from strawberry leaves. In this study, among the combinations of BAP and TDZ, the highest number of shoots formed per explant (5.5) was achieved with $4-\mu \mathrm{M}$ TDZ and $9-\mu_{\mathrm{M}} \mathrm{BAP}$; this treatment had significantly less shoot formation compared with all treatments containing TDZ alone (Fig. 2A). Nevertheless, in terms of percentage of explants producing shoots, this combination treatment had reasonably high shoot production (73\%) (Fig. 2B). These results confirm the importance of TDZ as a cytokinin for increasing shoot production and the percentage of strawberry leaves responding. This was also reported to be effective for shoot regeneration from strawberry shoot tips as well (Haddadi et al., 2010).

ShOot REgENERATION FROM SноOт TIPs. The effect of zeatin, kinetin, and 2ip has been demonstrated on regeneration and proliferation of many crops. In this study, the shoots formed on zeatin-containing medium elongated well and no callus formation was observed. These results are in accordance with those of Rowland and Ogden (1992) in highbush blueberry (Vaccinium corymbosum) and Gomes et al. (2010) in strawberry tree (Arbutus unedo). Meiners et al. (2007) reported that zeatin was very effective for shoot induction and shoot elongation of lingonberry (Vaccinium vitis-idaea). Debnath and Mcrae (2002) found that zeatin promoted shoot regeneration from leaves of lingonberry without a callus phase after 3 to 4 weeks of culture with darkness treatment for the first $7 \mathrm{~d}$. Shoot regeneration from shoot tips of 'Camarosa' strawberry required only 1 week of culture without a dark treatment. These differences are likely due to the effect of genotype, explant type, or both.

Some previous reports that compared the effect of cytokinins such 


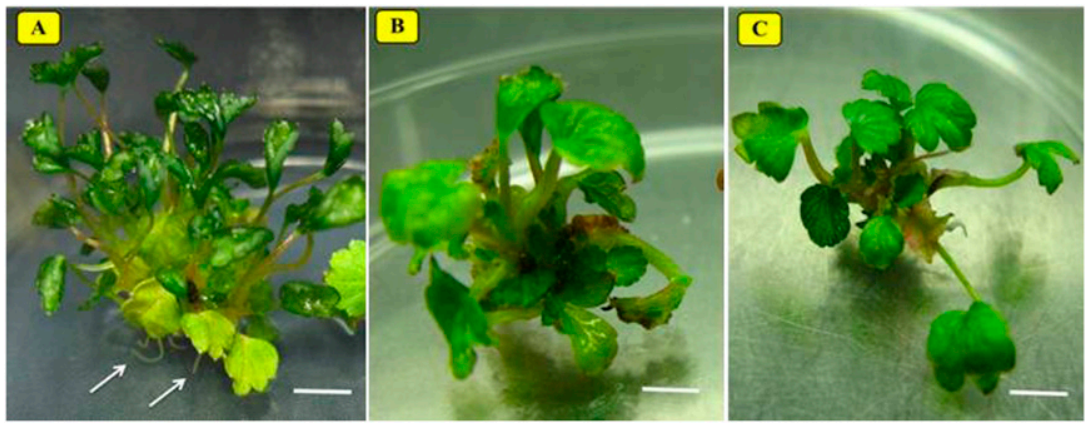

Fig. 4. Shoots obtained from shoot tips of strawberry after 3 weeks of culture on: (A) 4- $\mu$ M zeatin $(\mathrm{bar}=1 \mathrm{~cm}),($ B $) 16-\mu \mathrm{M}$ kinetin $(\mathrm{bar}=0.75 \mathrm{~cm}),(\mathrm{C}) 8-\mu \mathrm{M}$ 6 - $\alpha, \alpha$-dimethylallylamino purine $(2 \mathrm{ip})($ bar $=0.77 \mathrm{~cm})$. Arrows show root formation along with shoot proliferation; $1 \mathrm{~cm}=0.3937 \mathrm{inch}$.

as BAP, kinetin, and 2ip on shoot proliferation noted that the best responses were with BAP (Bhatt and Dhar, 2000; Buah et al., 2010; Rahman et al., 2004). However, BAP can induce hyperhydricity (Declerck and Korban, 1995; Shibli et al., 1997) and to avoid hyperhydricity, BAP should be replaced with $2 \mathrm{iP}$ or zeatin, which do not show such effects (Vardja and Vardja, 2001). Our results found that zeatin did produce hyperhydricity (Fig. 4A) but was more effective for regeneration than kinetin and 2ip; kinetin was found to be more effective for regeneration than 2 ip. In addition, kinetin promoted shoot elongation more than $2 \mathrm{ip}$. Gomes et al. (2010) obtained the same result for kinetin for strawberry tree after applying kinetin to the medium. In Indian wild strawberry (Fragaria indica), more shoots per explant and more explants producing shoots were achieved with kinetin compared with medium containing 2ip (Bhatt and Dhar, 2000).

Proliferated shoots of 'Camarosa' strawberry had a high rooting ability; shoots rooted well on cytokinin-free MS medium. This might be due to the high endogenous auxin concentrations found in strawberry plants. Lopez-Bucio et al. (2003) and Lohar et al. (2004) demonstrated that cytokinins inhibit the elongation of roots and formation of lateral roots. High concentrations of cytokinins can inhibit or delay root formation (Ben-Jaacov et al., 1991). In this study, roots started to emerge in treatments with zeatin after the first subculture. This observation was also documented by Debnath (2005), who found that shoot proliferation and root development occurred from strawberry sepal explants on 1- and $2-\mu \mathrm{M}$ zeatin after a $14-\mathrm{d}$ incubation in the dark. In this study, root formation along with shoot proliferation was also observed in the presence of kinetin and 2ip, but the percentage of shoot formation and number of shoots produced per explant were significantly higher in medium with zeatin. From an economical point of view, 2ip and kinetin cost less than zeatin; however, zeatin not only promotes cell division and axillary shoot formation along with root formation, but also prevents leaf and shoot senescence. Therefore, it would be better to use zeatin for shoot multiplication of 'Camarosa' strawberry from shoot tips.

Overall, the results of this study confirmed the importance of TDZ, a substituted phenylurea compound, and zeatin, a substituted adenine compound, as cytokinins to promote shoot regeneration in 'Camarosa' strawberry. Optimum shoot regeneration was achieved on moderate concentrations of these plant growth regulators.

\section{Literature Cited}

Ben-Jaacov, J., A. Ackerman, E. Tal, and G. Jacobs. 1991. Vegetative propagation of Alberta magna by tissue culture and grafting. HortScience 26:74-75.

Bhatt, I.D. and U. Dhar. 2000. Micropropagation of Indian wild strawberry. Plant Cell Tissue Organ Cult. 60: 83-88.

Buah, J.N., E. Danso, K.J. Taah, E.A. Abole, E.A. Bediako, J. Asiedu, and R. Baidoo. 2010. The effects of different concentrations cytokinins on the in vitro multiplication of plantain (Musa sp.). Biotechnology 9:343-347.
Chitra, D. and G. Padmaja. 2005. Shoot regeneration via direct organogenesis from in vitro derived leaves of mulberry using thidiazuron and 6-benzylaminopurine. Scientia Hort. 106:593-602.

Compton, M.E. and D. Gray. 1993. Shoot organogenesis and plant regeneration from cotyledons of diploid, triploid, and tetraploid watermelon. J. Amer. Soc. Hort. Sci. 118:151-157.

Debnath, S.C. 2005. Strawberry sepal: Another explant for thidiazuron-induced adventitious shoot regeneration. In Vitro Cell. Dev. Biol. Plant 41:671-676.

Debnath, S.C. and J.A. Teixeira da Silva. 2007. Strawberry culture in vitro: Applications in genetic transformation and biotechnology. Fruit Veg. Cereal Sci. Biotechnol. 1:1-12.

Debnath, S.C. and K.B. Mcrae. 2002. An efficient adventitious shoot regeneration system on excised leaves of micropropagated lingonberry (Vaccinium vitis-idaea L.). J. Hort. Sci. Biotechnol.77744-752.

Declerck, V. and S. Korban. 1995. Shoot regeneration from leaf tissues of Phlox paniculata L. J. Plant Physiol. 147:441446.

Dobranszki, J. and J.A. Teixeira da Silva. 2010. Micropropagation of apple-A review. Biotechnol. Adv. 28:462-488.

Gaafar, R. and M. Saker. 2006. Monitoring of cultivars identity and genetic stability in strawberry varieties grown in Egypt. World J. Agr. Sci. 2:29-36.

Gamborg, O.L., R.A. Miller, and K. Ojima. 1968. Nutrient requirement of suspension cultures of soybean root cells. Exp. Cell Res. 50:151-158.

Gomes, F., M. Simoes, M.L. Lopes, and J.M. Canhoto. 2010. Effect of plant growth regulators and genotype on the micropropagation of adult trees of Arbutus unedo L. (strawberry tree). New Biotechnol. 27:882-892.

Gruchala, A., M. Korbin, and E. Zurawicz. 2004. Conditions of transformation and regeneration of 'Induka' and 'Elista' strawberry plants. Plant Cell Tissue Organ Cult. 79:153-160.

Haddadi, F., A.A. Maheran, S. Ghizan, A.R. Azmi, and H. Kamaladini. 2010. Micropropagation of strawberry $\mathrm{cv}$. Camarosa. Prolific shoot regeneration from in vitro shoot-tips using thidiazuron with N6-benzylamino-purine. HortScience 45:453-456.

Husaini, A.M., S. Aquil, M. Bhat, T. Qadri, T. Kamaluddin, and M. Abdin. 2008. A high-efficiency direct somatic embryogenesis system for strawberry 
(Fragaria ananassa Duch.) cultivar Chandler. Crop Sci. Biotechnol. 11:100-107.

Husaini, A.M. and D.K. Srivastava. 2006. Plant regeneration and Agrobacteriummediated gene transfer studies in strawberry tissues (Fragaria xananassa Duch.). Asian J. Microbiol. Biotechnol. Environ. Sci. 8:671-678.

Khan, M.S., M. Usman, and M.I. Lilla. 2006. Facile plant regeneration from tomato leaves induced with spectinomycin. Pak. J. Bot. 38:947-952.

Landi, L. and B. Mezzetti. 2006. TDZ, auxin and genotype effects on leaf organogenesis in Fragaria. Plant Cell Rpt. 25:281-288

Lohar, D.P., J.E. Schaff, J.G. Laskey, J.J. Kieber, K.D. Bilyeu, and D.M. Bird. 2004. Cytokinins play opposite roles in lateral root formation, and nematode and rhizobial symboses. Plant J. 38:203-214.

Lopez-Bucio, J., A. Cruz-Ramyrez, and L. Herrera-Estrella. 2003. The role of nutrient availability in regulating root architecture. Curr. Opin. Plant Biol. 6:280-287.

Meiners, J., M. Schwab, and I. Szankowski. 2007. Efficient in vitro regeneration systems for Vaccinium species. Plant Cell Tissue Organ Cult. 89:169-176.

Mohamed, F.H., M.S. Beltai, M.A. Ismail, and G.F. Omar. 2007. High frequency, direct shoot regeneration from greenhouse-derived leaf disks of six strawberry cultivars. Pak. J. Biol. Sci. 10:96100.
Murashige, T. and F. Skoog. 1962. A revised medium for rapid growth and bioassays with tobacco tissue cultures. Physiol. Plant. 15:473-497.

Passey, A.J., K.J. Barrett, and D.J. James. 2003. Adventitious shoot regeneration from seven commercial strawberry cultivars (Fragaria $\times$ ananassa Duch.) using a range of explant types. Plant Cell Rpt. 21:397-401.

Rahman, M.Z., K.M. Nasiruddin, M.A. Amin, and M.N. Islam. 2004. In vitro response and shoot multiplication of banana with BAP and NAA. Asian J. Plant Sci. 3:406-409.

Rowland, L.J. and E. Ogden. 1992. Use of a cytokinin conjugate for efficient shoot regeneration from leaf sections of highbush blueberry. HortScience 27:11271129.

Sakila, S., M.B. Ahmed, U.K. Roy, M.K. Biswas, R. Karim, M.A. Razvy, M. Hossain, R. Islam, and A. Hoque. 2007. Micropropagation of strawberry (Fragaria $\mathrm{x}$ ananassa Duch.): A newly introduced crop in Bangladesh. Amer.-Eurasian J. Scientific Res. 2:151-154.

Sharif, I.M., C.H. Mohammud, and S.A. Kahar. 2006. Smart environmental control system for the production of strawberry in lowland tropics. Acta Hort. 710:457-464.

Shibli, R.A., M.A.L. Smith, and R. Nasr. 1997. Iron source and cytokinin mitigate the incidence of chlorosis and hyperhydratation in vitro. J. Plant Nutr. 20:773781.
Sorvari, S., S. Ulvinen, T. Hietarante, and H. Hiirsalmi. 1993. Preculture medium promotes direct shoot regeneration from micro-propagated strawberry leaf discs. HortScience 28:55-57.

Sriskandarajah, S., S. Frello, and M. Serek. 2001 . Induction of adventitious shoots in vitro in Campanula carpatica. Plant Cell Tissue Organ Cult. 67:295-298.

Vardja, R. and T. Vardja. 2001. The effect of cytokinin type and concentration and the number of subcultures on the multiplication rate of some decorative plants. Proc. Estonian Acad. Sci. Biol. Ecol. 50:22-32.

Voth, V., D.V. Shaw, and R.S. Bringhurst. 1994. Strawberry plant called Camarosa: United State Patent US PP08708. U.S. Patent Trademark Office, Washington, DC.

Yonghua, Q., Z. Shanglong, S. Asghar, Z. Lingxiao, Q. Qiaoping, C. Kunsong, and X. Changjie. 2005. Regeneration mechanism of Toyonoka strawberry under different color plastic films. J. Plant Sci. 168:1425-1431.

Zebrowska, J.I. and J. Hortynski. 2002. Plant regeneration from leaf explants in strawberry (Fragaria Xananassa Duch.). Acta Hort. 567:313-315.

Zhang, C.L., D.F. Chen, M.C. Elliott, and A. Slater. 2001. Thidiazuron-induced organogenesis and somatic embryogenesis in sugar beet (Beta vulgaris L.). In Vitro Cell. Dev. Biol. Plant 37:305-310. 